\title{
Treatment of SPG5 with cholesterol-lowering drugs
}

\author{
Andrea Mignarri $^{1}$ - Alessandro Malandrini ${ }^{1} \cdot$ Marina Del Puppo $^{2}$. \\ Alessandro Magni $^{2} \cdot$ Lucia Monti $^{3} \cdot$ Federica Ginanneschi $^{1} \cdot$ Alessandra Tessa $^{4}$. \\ Filippo Maria Santorelli ${ }^{4} \cdot$ Antonio Federico $^{1} \cdot$ Maria Teresa Dotti $^{1}$
}

Received: 26 October 2015/Revised: 2 November 2015/Accepted: 3 November 2015/Published online: 14 November 2015

(c) Springer-Verlag Berlin Heidelberg 2015

Dear Sirs,

Spastic paraplegia type 5 (SPG5) is an autosomal recessive hereditary spastic paraparesis (HSP) associated with pure or complicated phenotypes and mutations in CYP7B1 [1] causing an impairment of the alternative pathway of bile acid synthesis with marked accumulation of 27-hydroxycholesterol (27OHC) in plasma and cerebrospinal fluid [2]. Since brain $27 \mathrm{OHC}$ has an extracerebral origin [3], cholesterol-lowering drugs might prevent neurological impairment in SPG5 by reducing circulating 27OHC, which is derived from cholesterol.

We previously reported a nine-month follow-up in two ambulant siblings harboring mutations in SPG5/CYP7B1 [4]. At that time, we evaluated the effects of statin therapy in one of the two cases (patient 1) and observed moderate serum $27 \mathrm{OHC}$ reduction. Here, we present a 24-month follow-up in patient 1 , treated with simvastatin and ezetimibe, and a 12-month follow-up in patient 2, treated with ezetimibe alone.

Clinical details, laboratory and instrumental findings, and molecular data in the two patients have been described elsewhere [4]. In the present study, both subjects underwent neurological evaluation including Spastic

Maria Teresa Dotti

dotti@unisi.it

1 Unit of Neurology and Neurometabolic Disorders, Department of Medicine, Surgery and Neurosciences, University of Siena, Siena, Italy

2 Department of Health Sciences, Medical School, University of Milano-Bicocca, Milan, Italy

3 Unit of Diagnostic and Therapeutic Neuroradiology, Azienda Ospedaliera Siena, Siena, Italy

4 Unit of Molecular Medicine, IRCCS Stella Maris, Pisa, Italy
Paraplegia Rating Scale (SPRS) and Modified Rankin Scale (MRS) clinical scoring, routine blood tests, cholesterol and 27OHC determinations every 3 months, and instrumental follow-up including motor evoked potentials (MEPs), conventional brain magnetic resonance imaging (MRI), and MR spectroscopy every 6 months.

Patient 1 received different oral doses of simvastatin (from 20 to $60 \mathrm{mg} /$ day) during the first 12 months, and then oral ezetimibe $10 \mathrm{mg} / \mathrm{day}$ was added to simvastatin $40 \mathrm{mg}$ /day for 12 months. Treatments were well tolerated. Serum $27 \mathrm{OHC}$ concentration progressively decreased under treatment with simvastatin either alone (reduction ranged from 10 to $45 \%$ compared to baseline) or when in combination with ezetimibe (55\% decrease compared to baseline), and cholesterol tended to decrease in parallel with 27OHC (Fig. 1a). Association of simvastatin and ezetimibe was more effective in reducing $27 \mathrm{OHC}$ than the increase of simvastatin dosage up to $60 \mathrm{mg}$ /day. No changes of neurological disability as well as brain MRI and spectroscopic pattern were observed. MEPs revealed a trend toward improvement or stabilization of central motor conduction times (CMCTs).

Patient 2, who had not tolerated simvastatin because of cramps and marked hyperCKemia [4], received ezetimibe $10 \mathrm{mg} /$ day for 12 months, and tolerated well this therapy. We observed a persistent decrease of serum $27 \mathrm{OHC}$ values (38-50\% reduction compared to baseline), whereas cholesterol levels initially decreased and then returned to baseline (Fig. 1b). Alike his sister, SPRS and MRS scores as well as brain MRI and spectroscopy were unchanged. MEPs showed substantially stable CMCTs values over time.

Since chenodeoxycholic acid (CDCA) has been reported to be beneficial in a child with liver disease associated with a missense variant in $C Y P 7 B 1$ [5], we added oral CDCA 


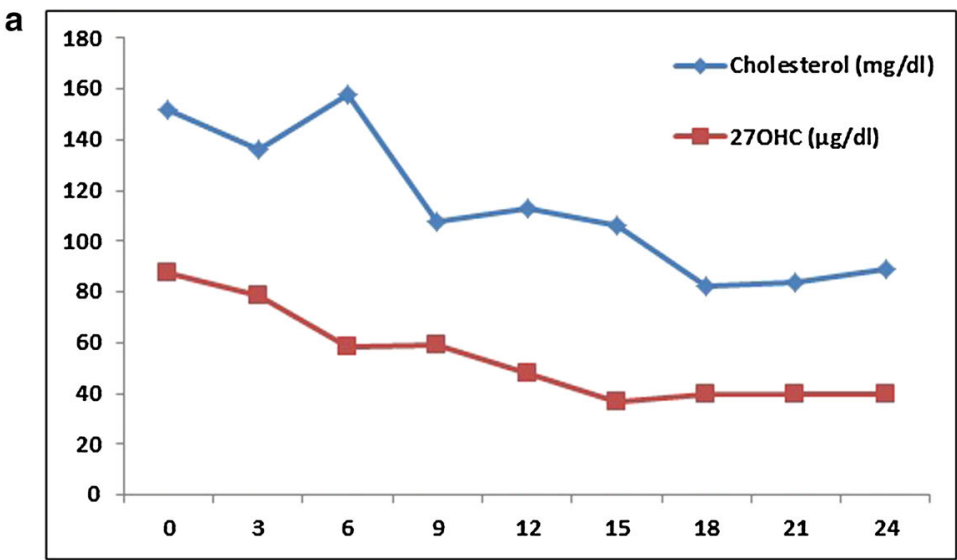

\begin{tabular}{|c|c|}
\hline Baseline & No treatment \\
\hline Month 3 & Simvastatin $20 \mathrm{mg}$ \\
\hline Month 6 & Simvastatin $\mathbf{4 0 ~} \mathbf{m g}$ \\
\hline Month 9 & Simvastatin $60 \mathrm{mg}$ \\
\hline Month 12 & Simvastatin $\mathbf{4 0} \mathbf{~ m g}$ \\
\hline Month 15 & Simvastatin $\mathbf{4 0} \mathrm{mg}$ + Ezetimibe $10 \mathrm{mg}$ \\
\hline Month 18 & Simvastatin $\mathbf{4 0} \mathrm{mg}$ + Ezetimibe $10 \mathrm{mg}$ \\
\hline Month 21 & Simvastatin $\mathbf{4 0} \mathrm{mg}$ + Ezetimibe $\mathbf{1 0 ~} \mathrm{mg}$ \\
\hline Month 24 & Simvastatin $\mathbf{4 0} \mathrm{mg}$ + Ezetimibe $10 \mathrm{mg}$ \\
\hline
\end{tabular}

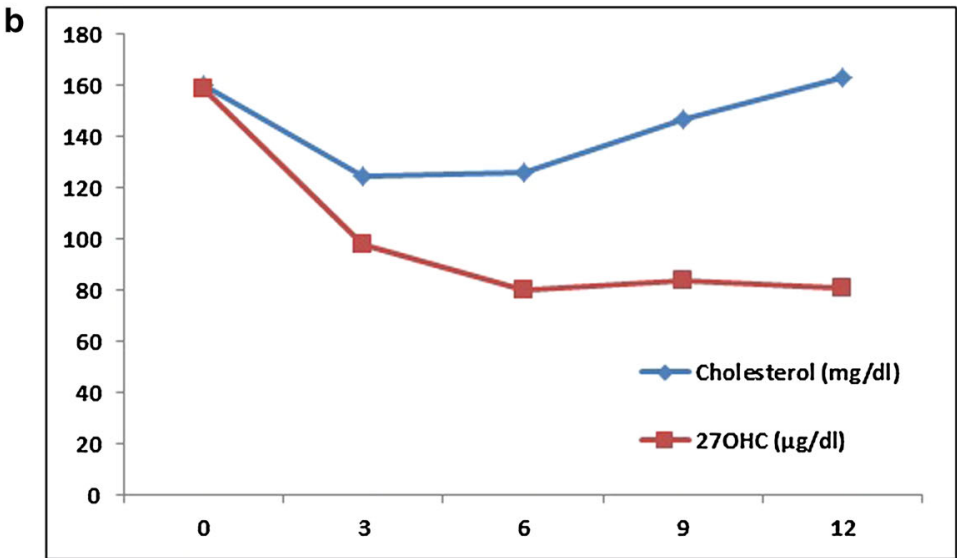

Baseline

Month 3

Month 6

Month 9

Month 12

\section{No treatment}

Ezetimibe $10 \mathrm{mg}$

Ezetimibe $10 \mathrm{mg}$

Ezetimibe $10 \mathrm{mg}$

Ezetimibe $10 \mathrm{mg}$
Fig. 1 a Serum cholesterol $(\mathrm{mg} / \mathrm{dl})$ and serum $27 \mathrm{OHC}(\mu \mathrm{g} / \mathrm{dl})$ levels over a 24-month follow-up period in patient 1 . b Serum cholesterol $(\mathrm{mg} / \mathrm{dl})$ and serum $27 \mathrm{OHC}(\mu \mathrm{g} / \mathrm{dl})$ levels over a 12-month follow-up period in patient 2. Normal values: cholesterol $130-200 \mathrm{mg} / \mathrm{dl}$; $27 \mathrm{OHC} 16 \pm 3 \mu \mathrm{g} / \mathrm{dl}$

However, more clinical meaningful endpoints should be defined before embarking in double-blind, placebo-controlled clinical trials assessing the efficacy of cholesterollowering drugs in SPG5. On the other hand, and based also on our own experience with multiple therapy in two sibs, we cannot draw firm conclusions on efficacy of CDCA in reducing $27 \mathrm{OHC}$ in adult $C Y P 7 B 1$-mutated patients.

Acknowledgments Authors would like to thank Gianluca Marangi for excellent nursing and Claudio Salvadori for laboratory assistance.

\section{Compliance with ethical standards}

Conflicts of interest We declare that we have no conflicts of interest.

Funding We declare no funding.

Ethical standard This study has been approved by the appropriate ethics committee and has therefore been performed in accordance with the ethical standards laid down in the 1964 Declaration of Helsinki. 


\section{References}

1. Tsaousidou MK, Ouahchi K, Warner TT, Yang Y, Simpson MA, Laing NG, Wilkinson PA, Madrid RE, Patel H, Hentati F, Patton MA, Hentati A, Lamont PJ, Siddique T, Crosby AH (2008) Sequence alterations within CYP7B1 implicate defective cholesterol homeostasis in motor-neuron degeneration. Am J Hum Genet 82:510-515

2. Schüle R, Siddique T, Deng HX, Yang Y, Donkervoort S, Hansson M, Madrid RE, Siddique N, Schöls L, Björkhem I (2010) Marked accumulation of 27-hydroxycholesterol in SPG5 patients with hereditary spastic paresis. J Lipid Res 51:819-823

3. Heverin M, Meaney S, Lütjohann D, Diczfalusy U, Wahren J, Björkhem I (2005) Crossing the barrier: net flux of 27-hydroxycholesterol into the human brain. J Lipid Res 46:1047-1052
4. Mignarri A, Malandrini A, Del Puppo M, Magni A, Monti L, Ginanneschi F, Tessa A, Santorelli FM, Federico A, Dotti MT (2014) Hereditary spastic paraplegia type 5: a potentially treatable disorder of cholesterol metabolism. J Neurol 261:617-619

5. Dai D, Mills PB, Footitt E, Gissen P, McClean P, Stahlschmidt J, Coupry I, Lavie J, Mochel F, Goizet C, Mizuochi T, Kimura A, Nittono H, Schwarz K, Crick PJ, Wang Y, Griffiths WJ, Clayton PT (2014) Liver disease in infancy caused by oxysterol $7 \alpha$ hydroxylase deficiency: successful treatment with chenodeoxycholic acid. J Inherit Metab Dis 37:851-861 